\title{
KAJIAN RUANG SAKRAL BAGI MILENIAL DI DALAM KREMATORIUM
}

\author{
Drama Permai ${ }^{1}$, Sutarki Sutisna ${ }^{2)}$ \\ 1)Program Studi S1 Arsitektur, Fakultas Teknik, Universitas Tarumanagara, dramapermai@gmail.com \\ 2) Program Studi S1 Arsitektur, Fakultas Teknik, Universitas Tarumanagara, sutarkis@gmail.com
}

\begin{abstract}
Abstrak
Budaya yang sangat kental di dalam masyarakat Indonesia semakin lama semakin memudar oleh generasi milenial seiring dengan berjalannya waktu. Salah satu budaya yang diambil sebagai contoh adalah budaya sembahyang leluhur, memudar dikarenakan tidak adanya mediator untuk mempelajari budaya tersebut. Pembelajaran budaya sembahyang leluhur dapat dipraktekan langsung di salah satu bangunan sakral, yaitu krematorium dan kolumbarium. Tujuan dari penelitian ini adalah untuk meneliti tipologi ruang krematorium yang cocok dengan perilaku generasi milenial dan bagaimana cara mengolah unsur suasana keruangan di dalam bangunan krematorium. Metode penelitian yang digunakan adalah pengumpulan data dari wawancara secara langsung, data internet dan buku, perbandingan studi preseden dan analisis sintesis. Krematorium ini dirancang untuk milenial dengan menekankan pada sebuah perjalanan yang akan dilakukan oleh para milenial. Permainan skala ruang, warna ruang, terang dan gelap ruang, dan suasana hiruk pikuk suasana di dalamnya akan menciptakan sebuah perjalanan sakral. Perjalanan ini diharapkan dapat menjadi acuan dimana para milenial dapat menyimpan sebuah pengalaman budaya dengan cara merasakan langsung suasana dan kegiatannya di setiap ruangnya yang akan menciptakan memory tersendiri bagi para milenial. Desain yang disajikan akan memisahkan 2 program utama yaitu massa sakral dan massa non-sakral yang dihubungkan dengan sebuah penghubung. Peran alam juga dimasukkan sebagai perpaduan antara dunia buatan dan dunia alam seperti bumi dimana dilapiskan oleh langit.
\end{abstract}

Kata kunci: Krematorium; Milenial; Perilaku; Perjalanan; Suasana

\begin{abstract}
A very thick culture in Indonesian society is increasingly fading away by the milenial generation over time. One culture that is taken as an example is the culture of ancestral prayer, fading due to the absence of mediators to study the culture. The learning of ancestral prayer culture can be practiced directly in one of the sacred buildings, namely the crematorium and the columbarium. The purpose of this study was to examine the typology of crematorium spaces that match the behavior of the milenial generation and how to process the spatial atmosphere elements in the crematorium building. The research method used is collecting data from direct interviews, internet data and books, comparison of precedent studies and synthesis analysis. The crematorium was designed for the milenial by emphasizing a journey that will be carried out by the milenials. Space scale, space colors, light and dark spaces, and the atmosphere inside will create a sacred journey. This Journey is expected to be a reference where milenials can save a cultural experience by directly sensing the atmosphere and activities in each of their spaces that will create a separate memory for the milenials. The design presented will separate the 2 main programs, namely the sacred mass and the nonsacred mass that is connected with a link. The role of nature is also included as a combination of the artificial world and the natural world such as the earth where the sky is superimposed.
\end{abstract}

Keywords: Atmosphere; Behavior; Crematorium; Journey; Milenials

\section{PENDAHULUAN}

Proses kremasi pada awalnya tidak terjadi di dalam sebuah bangunan. Proses ini bermula di sebuah pegunungan tinggi sebagai simbolisasi terhadap lokasi paling dekat dengan Tuhan. Setelah beberapa perubahan pola hidup pada masyarakat yang semakin modern, dibentuklah sebuah bangunan sebagai tempat kremasi dilakukan yaitu krematorium (CANA, 2019). 
Setelah jenazah leluhur yang sudah tiada telah menentukan akan dikremasi, terdapat 3 tempat peristirahatan terakhir para leluhur yaitu rumah abu, laut, dan makam. Rumah abu adalah sebuah tempat penyimpanan guci yang berisikan abu para leluhur yang dilanjutkan dengan sembahyang leluhur menurut budaya masing-masing. Budaya Tionghoa memiliki aturan dan hukum kremasi yang tidak terlepaskan dari cara dan proses pelaksanaan sembahyang leluhur yang sakral.

Generasi milenial terutama di ibukota seperti Jakarta yang sudah terpaku dengan sebuah gaya hidup yang sangat padat, mulai melupakan siklus kehidupan yang terus menerus berjalan dalam kehidupan mereka. Waktu yang sudah sangat padat ditambah dengan terbatasnya ilmu yang mengajarkan budaya tersebut juga membuat generasi milenial semakin lupa akan budaya sembahyang leluhur (Visioncritical, 2019).

Melihat pengaruh konteks budaya dalam masyarakat milenial terhadap desain arsitektur keagamaan, yaitu rumah abu dan krematorium dan pengaruh keruangan yang menciptakan sebuah pengalaman ruang tersendiri di setiap event yang terjadi disaat para generasi milenial menjalani sebuah perjalanan kebudayaan di dalam bangunan ini. Dengan terciptanya sebuah ingatan atau memory tersendiri terhadap keruangan ini.

\section{KAJIAN LITERATUR}

\section{Krematorium}

Krematorium adalah sebuah tempat dilaksanakannya prosesi kremasi (pembakaran jenazah manusia menjadi abu). Pembelajaran tipologi berdasarkan studi kasus menghasilkan kesimpulan sebagai berikut :

- Kremasi sangat berdekatan dengan jalur sirkulasi ambulans yang memudahkan proses perpindahan

- Memiliki bentuk ruang yang fungsional yaitu persegi panjang yang sesuai juga dengan bentuk alat kremasi.

- Memiliki ruang upacara sendiri untuk melakukan ritual pelepasan jiwa jenazah Proses kremasi pada setiap aliran agama berbeda-beda. Gambaran prosesi kremasi secara umum adalah sebagai berikut :

- Kremasi (Pembakaran menggunakan kayu/listrik/gas)

- Abu (Pengubahan fisik jenazah yang tersisa menjadi abu)

- Dititipkan (rumah abu), dilarungkan (laut), ditanam (makam)

\section{Kolumbarium}

Kolumbarium / Rumah Abu berasal dari bahasa latin Columba yang berarti merpati yang merupakan tempat publik yang digunakan untuk menyimpan guci berisikan abu jenazah yang akan ditaruh di sebuah lemari penyimpanan berukuran 30x40x40 cm (setiap ktaok guci).

Kolumbarium merupakan tempat terjadinya proses budaya sembahyang leluhur yang dilaksanakan setiap tahunnya oleh beberapa orang yang menganut budaya Tionghoa. Pembelajaran tipologi berdasarkan studi kasus menghasilkan kesimpulan sebagai berikut :

- Memiliki ruang yang memiliki kapasitas cukup banyak dalam menampung guci. dapat dibantu dengan perancangan lemari/rak yang dapat menampung banyak guci.

- Fungsional dan tidak terlalu tinggi (langit-langitnya) untuk memudahkan penggapaian lemari.

- Memiliki meja sembahyang yang dapat dipakai oleh setiap keluarganya dalam melaksanakan sembahyang leluhur.

\section{METODE}

Data yang digunakan sebagai sumber dan pondasi dalam perancangan proyek arsitektur ini adalah hasil survey tertulis generasi milenial terhadap budaya, studi perbandingan beberapa bangunan sejenis, teknis proses kremasi dan sembahyang leluhur, hasil survey lapangan 
mengenai tapak dan sekelilingnya, dan zonasi dan peraturan bagi pembangunan bangunan kremasi dan rumah abu.

Dimulai dengan mengadakan Survey lapangan yang mengambil data tangible dan intangible secara langsung di tempat. Kemudian melakukan wawancara secara langsung dan dengan membagikan kuisioner untuk mendapatkan data milenial dan data dasar mengenai isu dan program. Studi literatur dan preseden yang didapat dari buku dan internet sebagai data pendukung.

Data yang diperoleh dari sumber yang telah disebutkan diatas akan diolah dan dianalisis dengan membandingkannya satu sama lain agar menciptakan sebuah pemikiran baru terhadap bangunan yang dapat diterapkan dan menghasilkan sebuah sintesa pemikiran berupa sebuah produk baru yang kemudian akan diterapkan ke dalam proses perancangan. Hasil sintesa dapat berupa bentuk program, ide suasana ruang, ide pengalaman ruang, perancangan eksterior bangunan, dan pengelolaan lanskap bangunan.

\section{DISKUSI DAN HASIL}

\section{Permintaan Millenial Terhadap Proyek}

Kebutuhan ruang kremasi dan rumah mengalami perubahan dari segi pengalaman ruangnya dan fasilitas yang disajikan untuk generasi milenial. Permintaan milenial sudah dikumpulkan berdasarkan hasil penyebaran form yang dapat dilihat dibawah sebagai pembantu perancang dalam mempertimbangkan kebutuhan ruang para milenial.

Kesimpulan dari pengambilan hasil pembagian form, dapat disimpulkan bahwa generasi milenial membutuhkan ruang kremasi dan peyimpanan abu seperti berikut:

- Ruang yang sejuk (kalau bisa menggunakan AC).

- Ruang yang memiliki konektivitas dengan internet yang tinggi.

- Ruang hijau sebagai ruang penyejuk dan ruang tunggu.

- Ruang kumpul keluarga sebagai tempat berkumpul.

- Ruang yang tidak terlalu berasap dan tidak berdebu.

- Ruang yang tidak terasa menyeramkan sepanjang perjalanan agar suasana tidak menyeramkan.

- Ruang yang tidak terlalu berdempetan dengan para penduka lainnya agar tidak kesusahan saat melaksanakan proses sembahyang leluhur.

- Ruang yang bersih dan terawat dengan baik.

- Masih kurang modern yang tidak sesuai dengan gaya generasi milenial.

Kesimpulan dari pengambilan hasil pembagian form, dapat disimpulkan bahwa generasi milenial membutuhkan ruang pembelajaran budaya seperti berikut:

- Pembelajaran mengenai proses sembahyang leluhur dengan detail.

- Pembelajaran mengenai asal usul budaya Tionghoa.

- Pembelajaran mengenai upacara yang dilakukan disaat proses kremasi agar mengetahui maksud dan tujuan dari upacara tersebut. 


\section{Program Tapak}

\section{PERSENTASE PROGRAM RUANG}

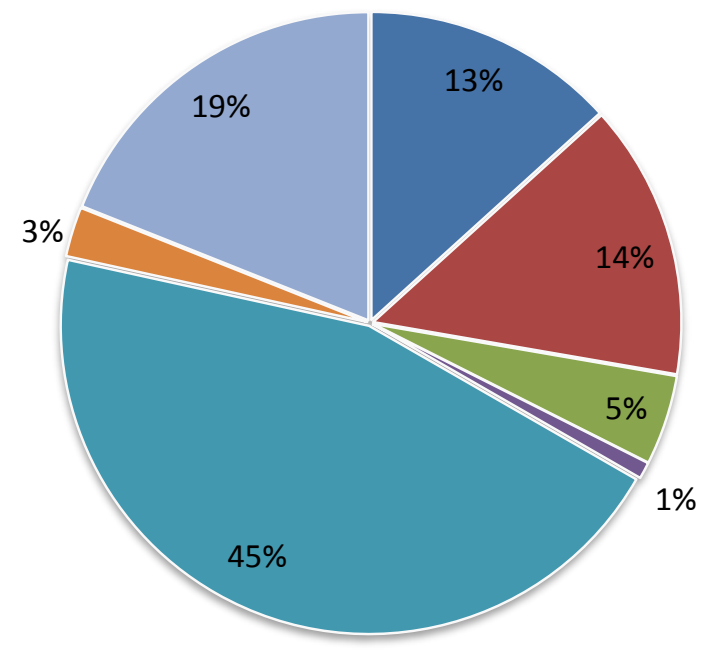

- RUANG GATHERING

RUANG PEMBELAJARAN

- RUANG DUKA

- RUANG KREMASI

- RUANG PENYIMPANAN ABU

KANTOR PENGELOLA

SERVIS

Gambar 1. Program Bangunan

Sumber: Penulis, 2019

\section{Studi Kasus}

Studi ini dilakukan untuk mendapatkan alur perjalanan dari masuk ke dalam bangnanan sampai keluar bangunan, ukuran standar ruang, kapasitas, faktor-faktor yang mengikat dan yang bebas dalam merancang bangunan koolumbarium dan krematorium. Penjabarannya tersajikan di bagian lampiran.

Kesimpulan yang dapat diambil adalah sebagai berikut :

- Bangunan yang terbentuk rata-rata memiliki massa yang

- berbentuk persegi panjang dan persegi. Hal ini disebabkan oleh efisiensi pemakaian ruang.

- Di setiap ruang dan unsur yang dimasukan ke dalam bangunan memiliki cerita sebuah perjalanan yang dihubungkan dengan filosofi china.

- Persentase program ruang dan contoh besaran standar di setiap bangunan sebagai pemicu pembuatan program ruang.

- Alur dan sirkulasi yang memiliki cerita sendiri dari awal sampai dengan akhir.

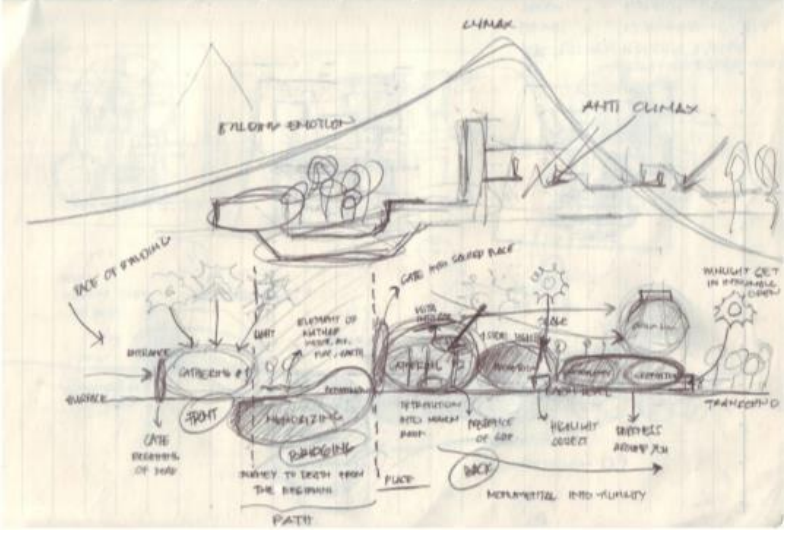

Gambar 2. Sketsa Konsep Bangunan

Sumber: Penulis, 2019 


\section{Pemilihan Tapak}

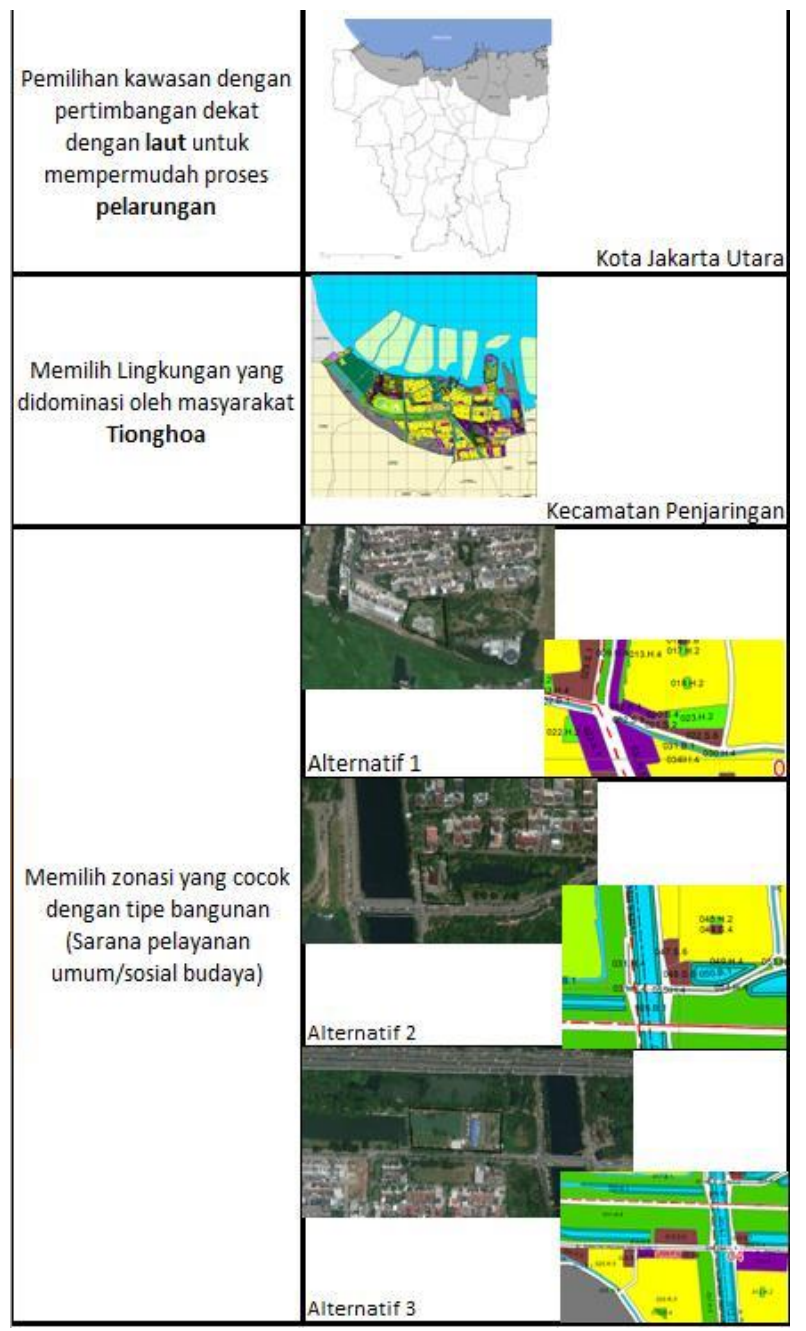

Gambar 3. Pemilihan Tapak

Sumber: Penulis, 2019

Berikut akan dijabarkan dasar untuk menentukan tapak dari ketiga alternative tersebut. Dari ketiga alternatif tapak yang dipilih, alternative 3 adalah tapak yang paling cocok untuk bangunan krematorium. Tapak ini terletak di Jalan Pantai Indah Selatan 1, Jakarta Utara, DKI Jakarta.

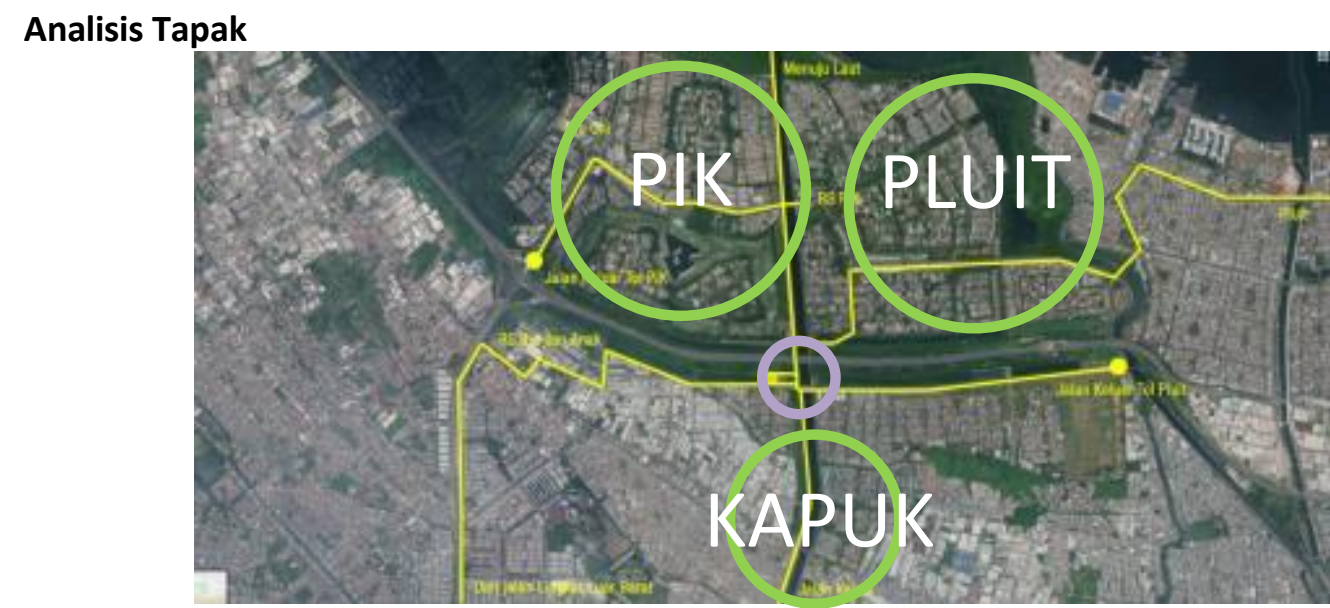

Gambar 4. Lokasi Tapak

Sumber : https://snazzymaps.com 


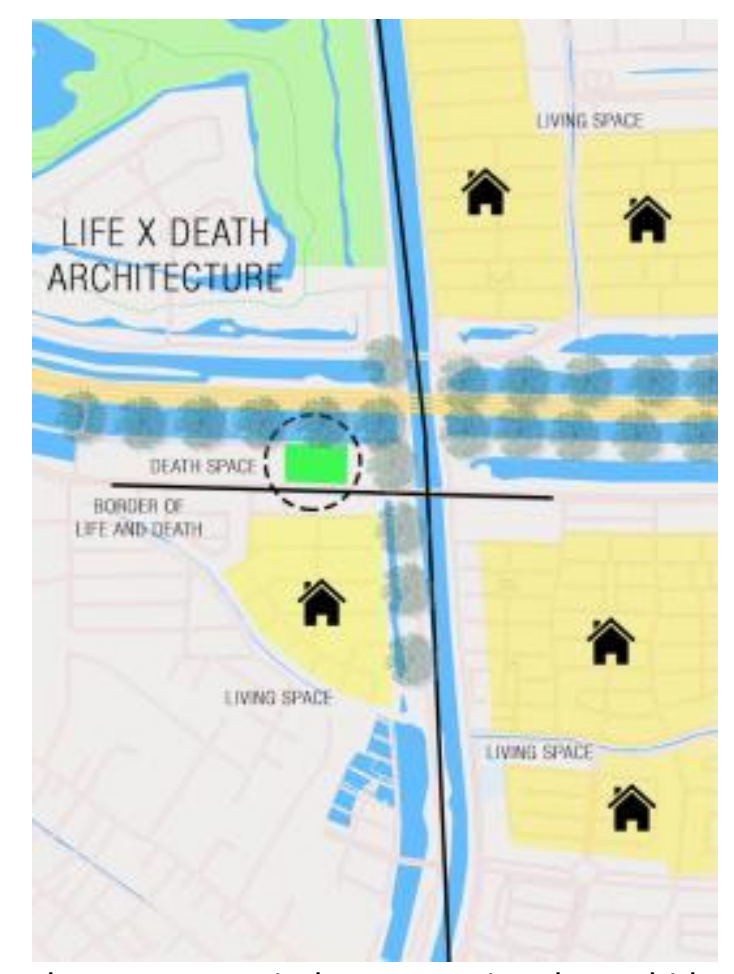

Gambar 5. Peta Arsitektur Kematian dan Kehidupan Sumber : https://snazzymaps.com

Arsitektur kematian memiliki hukum yaitu tidak boleh bersebelahan dengan pemukiman / tempat tinggal para penduduk. Diantara kedua arsitektur tersebut, harus mempunyai pembatas diantara mereka. Di dalam tapak ini pembatasnya berupa barisan pertama dan kedua dari depan tapak yang berupa tanah kosong dan bangunan penyediaan air minum. Di kedepannya tanah kosong tersebut akan didirikan sebuah kantor pemerintahan agar aktivitas disana akan lebih ramai karena kawasan Pantai Indah Selatan akan menjadi kawasan seperti PIK.

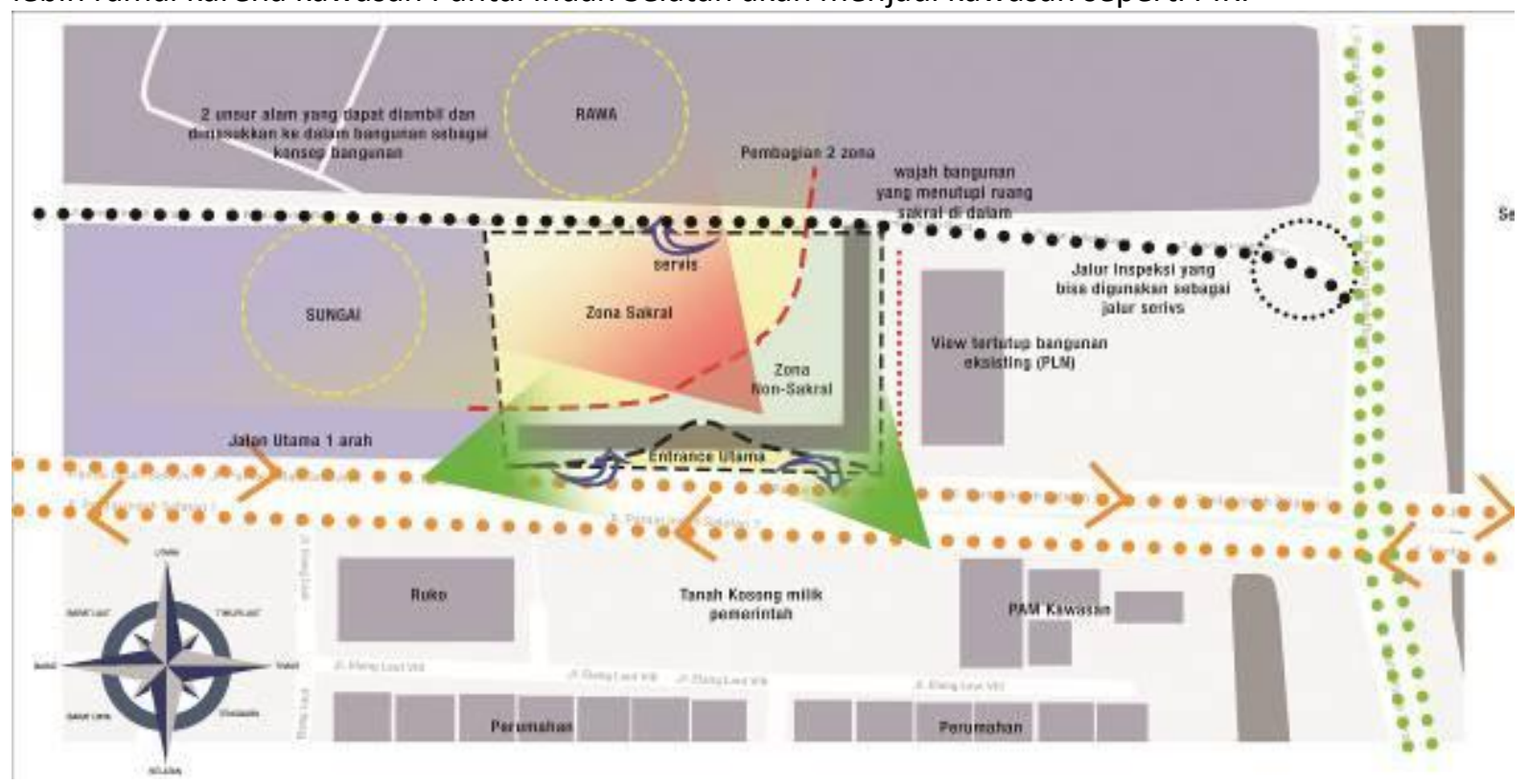

Gambar 6. Analisa Mikro Tapak

Sumber: Penulis, 2019 
Tapak dibagi menjadi 2 bagian yaitu zona sakral dan zona non-sakral. Zona sakral berorientasikan menuju kea lam disekitar tapak yaitu sungai dan rawa, sedangkan zona nonsakral orientasinya menuju kea rah depan dan samping yang tertutup bangunan PLN yang dimaksudkan bangunan non-sakral menjadi muka bangunan dan tidak terkesan angker dan dapat menutup bangunan sakral yang memiliki kesan tersembunyi dan tidak terlihat secara langsung. View yang terbentuk dari luar ke dalam adalah bangunan non-sakral dan dari dalam ke luar (zona sakral) mendapatkan view menuju sungai dan rawa.

Jalan Inspeksi di belakang tapak dijadikan sebagai jalur servis karena jalannya berukuran kecil dan jarang dipakai oleh masyrakat umum.

\section{Konsep Bangunan}

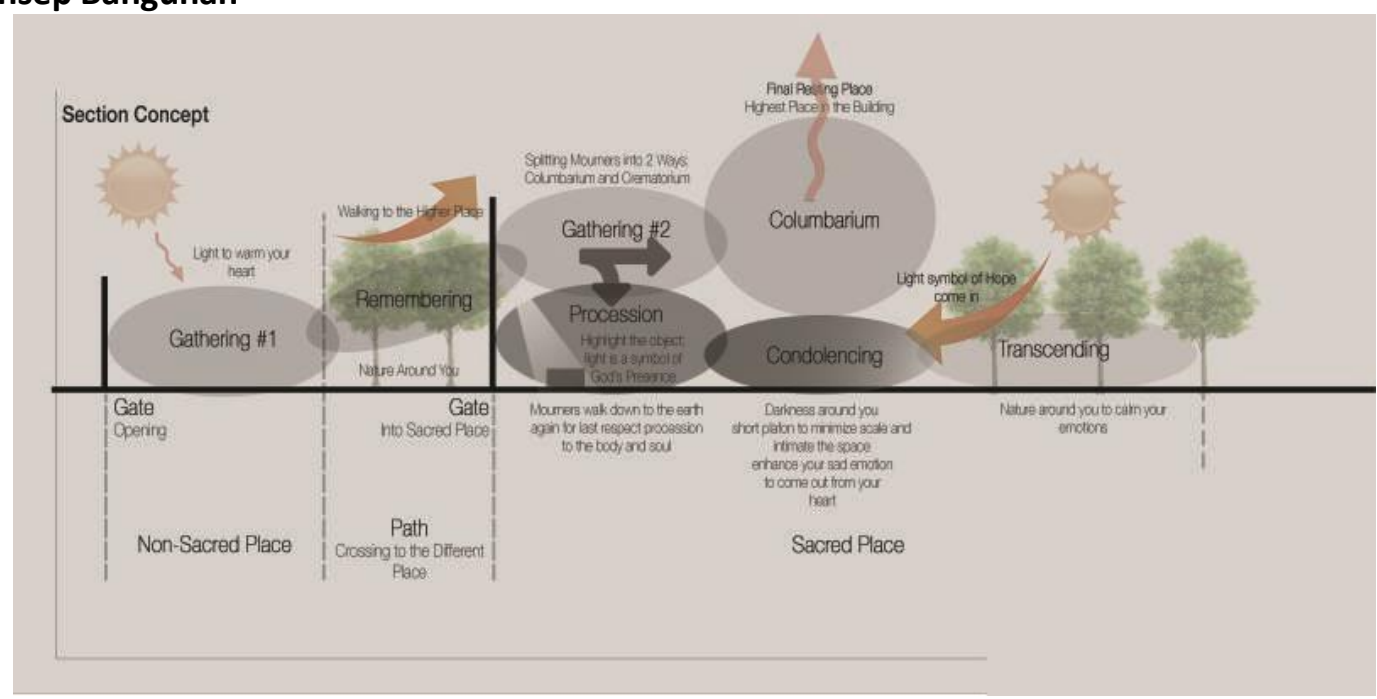

Gambar 7. Konsep Potongan

Sumber: Penulis, 2019

Potongan konsep diatas menjelaskan bagaimana sebuah suasana ruang dapat mempengaruhi ruangan tersebut menjadi ruang yang sakral. Ruangan tersebut memiliki penanda ruang sakral yang dapat dilihat dari gambar 10.

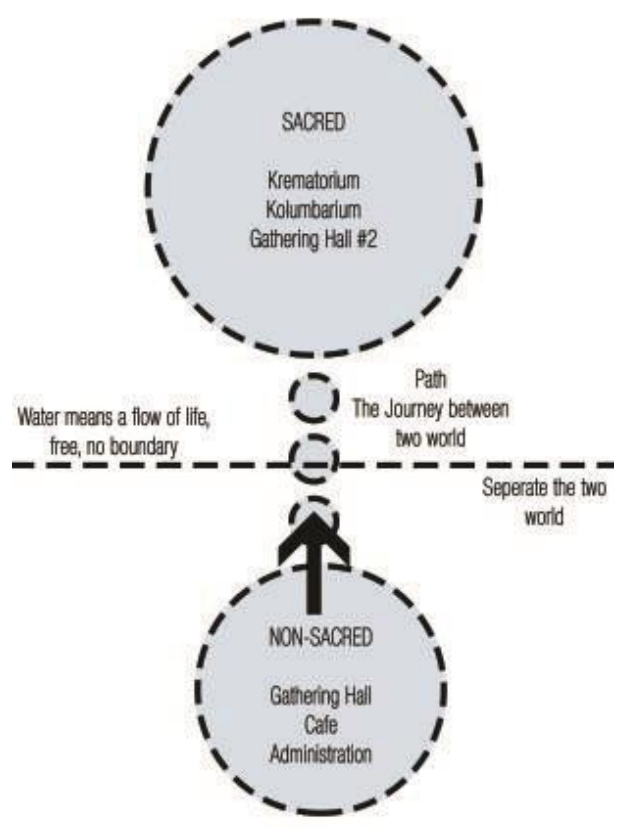

Gambar 10. Pemisahan Zona Bangunan Sumber: Penulis, 2019 


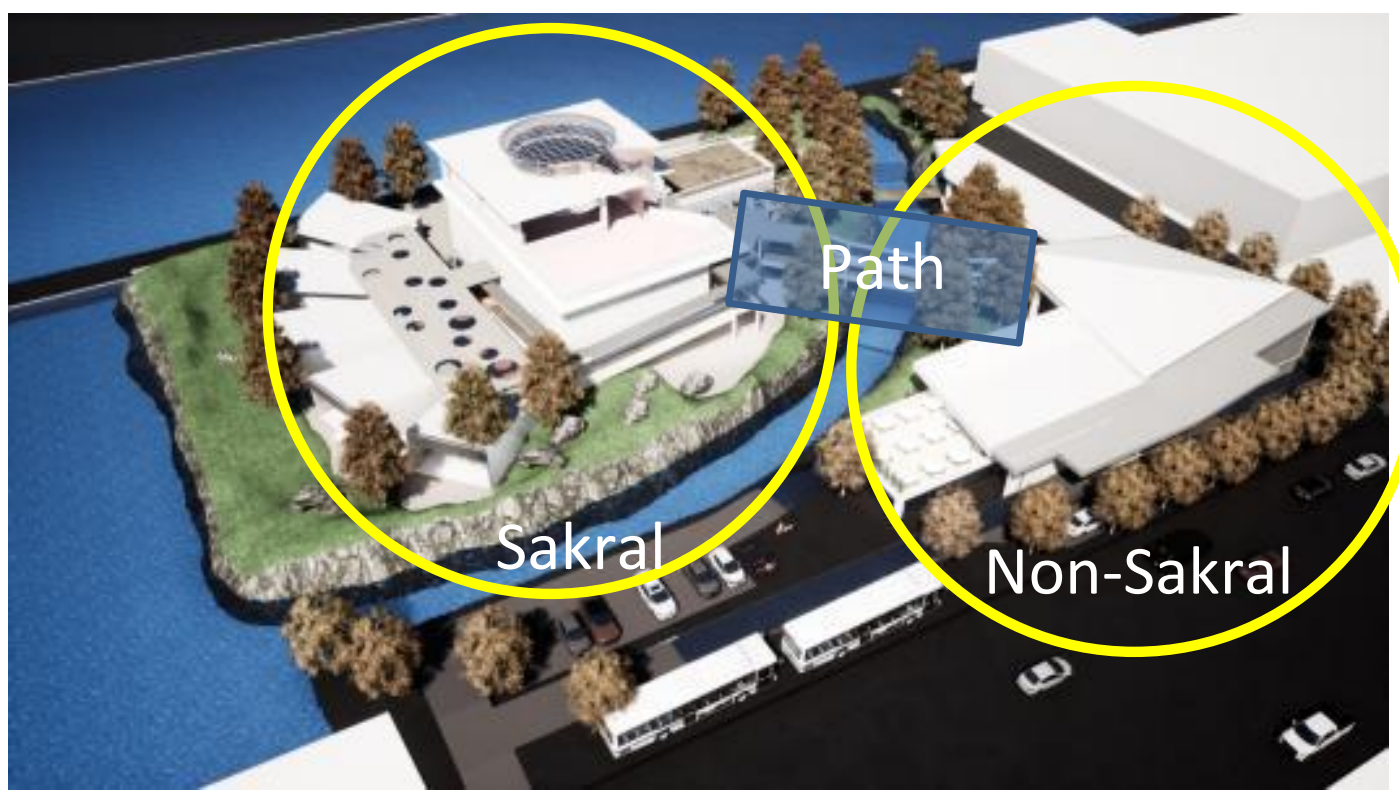

Gambar 11. Program

Sumber: Penulis, 2019

Pemisahan antara 2 massa utama dikarenakan kedua massa sakral dan non-sakral ini adalah kedua massa yang tidak bisa dipisahkan di dalam bangunan Krematorium. Massa non-sakral berfungsi sebagai massa penerima dan ruang tunggu untuk para penduka, sedangkan massa sakral berfungsi sebagai massa utama terjadinya proses kremasi, dan penghormatan terakhir arwah yang sudah meninggalkan kerabatnya. Kedua massa ini kemudian dihubungkan dengan sebuah transisi yaitu sebuah jalan linear yang menjadi awal mula perjalanan dari dunia kita menuju dunia yang berbeda yang kita tidak tahu sebelumnya.

Perjalanan ini dimulai dari massa non-sakral, yang mengumpulkan para kerabat penduka untuk bertemu sapa dan berkumpul di satu ruang yang besar dan terbuka. Ruangan ini dirancang dengan suasana yang hangat, terang, tidak terlalu ramai dan dekat dengan alam sebagai peneduh hati yang sedih.

Dilanjutkan dengan perjalanan yang melewati air sungai diantara 2 massa yang melambangkan pemisah antara 2 massa (dunia yang berbeda, sakral dan non-sakral) dan waktu yang terus mengalir di dalam dunia. Perjalanan ini dirancang dekat dengan alam sekitarnya, jalan yang lurus dan fokus ke massa sakral, dan ramp yang meninggi kearah massa sakral.

Massa Sakral adalah tujuan akhir dari perjalanan ini yang dirancang menjadi 4 bagian, yaitu ruang sembahyang, ruang kremasi, ruang pelepasan, dan ruang penyimpanan abu. ruang sembahyang dirancang pencayaannya agar objek utama dalam ruangan dapat disinari cahaya sebagai penentu fokus utama objek. Ruang kremasi dirancang dengan skala langit-langit yang sempit sebagai penguat rasa sedih di dalam hati para penduka agara seluruh emosi dari penduka dapat keluar. Ruang pelepasan dirancang dengan ruang yang terbuka, tidak berpenutup, dan langsung terhubung dengan alam sekitar. Dan terakhir adalah ruang penyimpanan abu yang diletakkan di lantai 2 dan 3 sebagai ruang yang paling tinggi di massa bangunan dan penanda tempat peristirahatan paling agung. 


\section{KESIMPULAN DAN SARAN}

Perkembangan arsitektur yang berkembang sangat pesat di setiap generasinya membuat para arsitek harus memikirkan arsitektur apa yang cocok dengan jaman sekarang. Perkembangan tipe arsitektur dan modelnya sangat berkaitan erat dengan perilaku yang dilakukan oleh para pengguna arsitektur. Pada ruang lingkup ini, arsitektur menjadi faktor penting dalam mengontrol perilaku atau beradaptasi dengan perilaku yang dilakukan para penggunanya.

Pembangunan bangunan krematorium dan kolumbarium ini diharapkan dapat membantu dan mengingatkan kembali para generasi millennial dengan jati diri dan budaya mereka sendiri yang telah diturunkan dari generasi ke generasi. Permainan suasana ruang yang dapat memberikan kesan tersendiri bagi generasi millennial untuk menciptakan sebuah memori yang dapat diwariskan turun-temurun ke generasi selanjutnya.

\section{REFERENSI}

Hasibansyah, O. (2005). Pendekatan Fenomenologi : Pengantar Praktik Penelitian dalam Ilmu Sosial dan Komunikasi, hh. 163-179.

Hoffman R., Douglas. Seeking the Sacred in Contemporary Religious Architecture, Cleveland State University's, hh. 1-76.

Khaliesh, H. (2014). ARSITEKTUR TRADISIONAL TIONGHOA : Tinjauan Terhadap Identitas, Karakter Budaya dan Eksistensinya, Fakultas Teknik Universitas Tanjungpura, Indonesia, 2014. hh. 86-99.

Putri Raharjo, Steffi. Sastra Tionghoa Universitas Kristen Petra Surabaya, 2016. Sembahyang Leluhur di Rumah, https://www.tionghoa.info/pemujaan-leluhur-di-rumah/

Schulz, C. N. (1971). Great Britain Studio Vista Limited. Existence, Space \& Architecture, Chapter 3 : Architectural Space, hh. 37-96.

Yanuar, S. P. (2016), Theoritical Review, Teori Perbedaan Generasi. hh. 125-134.

Wikinson, T. (2016). The Architectural Review, Typology : Crematorium, hh 1-21. 
